\title{
SCHISTOSOMAL PULMONARY ARTERIAL HYPERTENSION IN EAST AFRICA
}

\author{
BY \\ PETER P. TURNER \\ From the Department of Medicine, Mulago Hospital, Kampala, Uganda
}

Received July 4, 1963

Schistosomal cor pulmonale is common in Egypt where schistosomiasis is endemic (Day, 1937; Shaw and Ghareeb, 1938; Bedford, Aidaros, and Girgis, 1946; Erfan et al., 1949; Kenawy, 1950; Girgis, 1952; Farid et al., 1959). It is also well known in South America, particularly in Brazil (Lopes de Faria et al., 1957; Cavalcanti et al., 1962), and in Puerto Rico (Clark and Graef, 1935; Marchand et al., 1957; Rodríguez et al., 1963). Sporadic cases have been described from West Africa (Edington, 1957; Lauckner, Rankin, and Adi, 1961; Ogunlesi, 1962), and one from Southern Rhodesia (Gelfand, 1957). However, it is rare in Central Africa, as is illustrated by the fact that Gelfand in 1950 reported 400 necropsies in Africans suffering from bilharzia without finding a single example of cor pulmonale.

In spite of the fact that schistosomiasis is endemic in various parts of East Africa, only one patient has been described (Williams, 1958). This patient was seen in 1953 and had evidence of severe pulmonary arterial hypertension. The cause was unsuspected during life and was only shown to be schistosomal at necropsy.

The purpose of this paper is to present 5 further cases, 1 from coastal Kenya and 4 from Uganda. Of these 5, 4 were diagnosed during life.

\section{CASE REPORTS}

Case 1. B.M., a Duruma, Kenya coastal boy, aged 9 years, was admitted to hospital complaining of abdominal pain and swelling for six months. He also complained of fever and headache. He came from an area where $S$. hamatobium is endemic. On examination he was found to have odema of the ankles and a non-tender liver of normal consistency enlarged to the level of the umbilicus. The spleen was just palpable. The jugular venous pressure was normal. The apex beat was one inch beyond the mid-clavicular line in the fifth space, there was a left parasternal heave, and a loud third heart sound was heard. The basal second sound was narrowly split, widened in inspiration, and the pulmonary element was considerably accentuated. There were no murmurs or ejection systolic clicks, even after exercise. The blood pressure was $80 / 50 \mathrm{~mm}$. Hg. An electrocardiogram (Fig. 1) showed evidence of right ventricular enlargement (Grade 3, Goodwin and Abdin, 1959) with extensive inversion of the $T$ waves across the præcordium. Radiology and fluoroscopy showed considerable enlargement of the pulmonary arteries which were not excessively pulsatile. There was also enlargement of the right atrium and ventricle. The left heart was normal. The lung fields showed a miliary type of mottling in all zones. Although the examination of many specimens of stool was unhelpful, biopsy of the rectal mucosa revealed numerous ova of $S$. hamatobium. No abnormalities were ever found in the urine. His hæmoglobin level was $10.5 \mathrm{~g} . / 100 \mathrm{ml}$. and he had an eosinophilia of 24 per cent of a total white cell count of $5400 / \mathrm{c}$. mm. A liver biopsy showed evidence of cellular damage but none of cirrhosis and no schistosome ova were found. A lung biopsy was taken at open operation and was reported on as follows: "There is intimal arterial thickening at the level of the small muscular arteries and there are also a few small peri-arterial and peri-bronchial granulomata. It seems reasonable, in the presence 


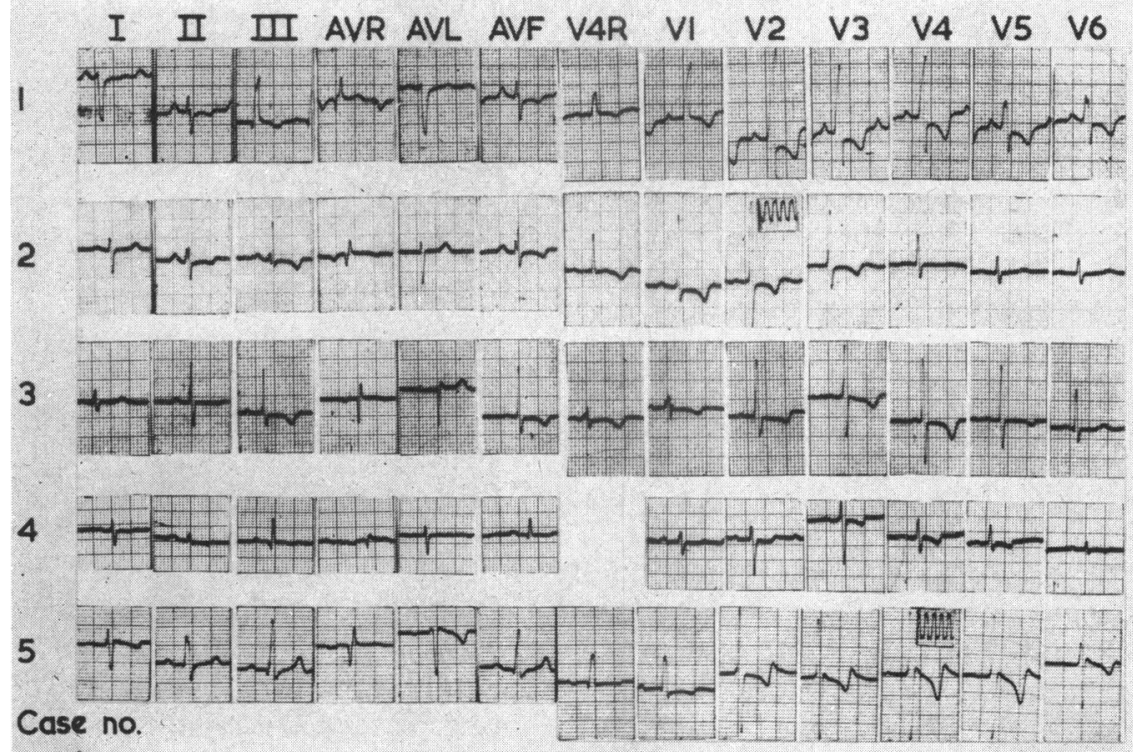

Fig. 1.-Electrocardiograms from Cases 1 to 5. Case 1: Grade 3 right ventricular hypertrophy. Peaked $P$ waves of normal voltage and steep $T$ wave inversion across the præcordium. Right axis deviation and dominant $R$ waves in V4R to V4 are seen. Case 2: Grade 3 right ventricular hypertrophy (note the re-standardization from V2 to V6). Case 3: Grade 1 right ventricular hypertrophy with extensive $T$ wave inversion across the præcordium. Increasing negativity of the T wave from V2 to V4. Case 4: Absence of dominant $R$ waves over the right præcordium with extensive $T$ wave inversion of increasing negativity from V2 to V4. Case 5: Grade 3 right ventricular hypertrophy with steep $T$ wave inversion across the præcordium and increasing negativity from V2 to V4 (note the restandardization from V4 to V6).

of these granulomata and of ova (three were found) to assume that the arterial lesions, and therefore the clinical pulmonary hypertension, are in fact secondary to pulmonary bilharzia".

Case 2. A.M., a Madi boy, aged 17 years, came from the West Nile district of Uganda, where $S$. mansoni is endemic. He complained of abdominal swelling and of inconstant pain in the splenic area for two years. He had an unproductive cough but was not breathless on exertion. On examination he was not anæmic or cyanosed, but marked clubbing of the fingers and toes was seen. The liver was just palpable and the spleen was enlarged to below the umbilicus. The jugular venous pressure was normal. The heart was not clinically enlarged. A left parasternal heave was present, the pulmonary second sound was palpable, a loud ejection systolic click was heard at the pulmonary area and both atrial and third heart sounds were heard. The pulmonary element of the widely split, but not fixed, basal second sound was accentuated, and after exertion an ejection systolic murmur and pulmonary diastolic (Graham-Steell) murmurs were heard. The blood pressure was $110 / 80 \mathrm{~mm}$. Hg. The hæmoglobin was $14.0 \mathrm{~g} . / 100 \mathrm{ml}$. and the white blood count $4200 / \mathrm{c} . \mathrm{mm}$. with 22 per cent eosinophils. The urine was normal. Examination of stools showed many ova of $S$. mansoni. A chest radiograph (Fig. 2) showed large pulmonary arteries and a large right atrium and ventricle. There was miliary mottling throughout the lung fields. An electrocardiogram (Fig. 1) showed evidence of Grade 3 (Goodwin and Abdin, 1959) right ventricular hypertrophy with marked T wave inversion over the right præcordium. A liver biopsy showed two characteristic schistosomal granulomata, one of which contained an ovum of S. mansoni. There was no evidence of cirrhosis. Repeated sputa were examined and characteristic ova of $S$. mansoni were found in several. It is of interest that the ova in the sputum were never viable, though those found in the stool always were. Right heart catheterization for technical reasons was confined to pressure readings. His systemic arterial oxygen saturation was 96 per cent by Brinkman hæmoreflector. The right atrial pressure was $12 / 4$, right ventricular pressure $115 / 0 / 10$, and pulmonary arterial pressure $115 / 42 \mathrm{~mm}$. Hg. 
Case 3. O.T., a Lugbara male, aged 20 years, came from the West Nile district of Uganda where $S$. mansoni is endemic. He complained that for one year he had had a persistent unproductive cough. For seven months he had had dizziness on running or working hard, and if he persisted in working hard he would fall down suddenly and lose consciousness. For six months he had noticed blood in the sputum in the early morning. On examination he had finger clubbing but no cyanosis. The jugular venous pressure was not raised, but the dominant wave was an "a" wave. The heart was not clinically large, there was a right ventricular heave, and a pulmonary ejection systolic murmur was heard but no ejection click. The basal second sound was widely split and fixed; the pulmonary element was slightly accentuated. An atrial sound was heard. These signs did not change after exercise. The blood pressure was $130 / 90 \mathrm{~mm}$. Hg. A chest radiograph showed enlargement of the pulmonary conus and pulmonary arteries, and a large right atrium. There was no mottling in the lung fields, and the peripheral vascular markings were normal. An electrocardiogram (Fig. 1) showed a dominant $R$ wave in V4R and V2, and marked $T$ wave inversion extending across the præcordium as far as V5. The hæmoglobin was $16.8 \mathrm{~g} . / 100 \mathrm{ml}$, and there was an eosinophilia of 20 per cent of a total white cell count of $3400 / \mathrm{c} . \mathrm{mm}$. Numerous stools and specimens of sputum were examined but no bilharzia ova were found. Only on taking rectal mucosal snips a

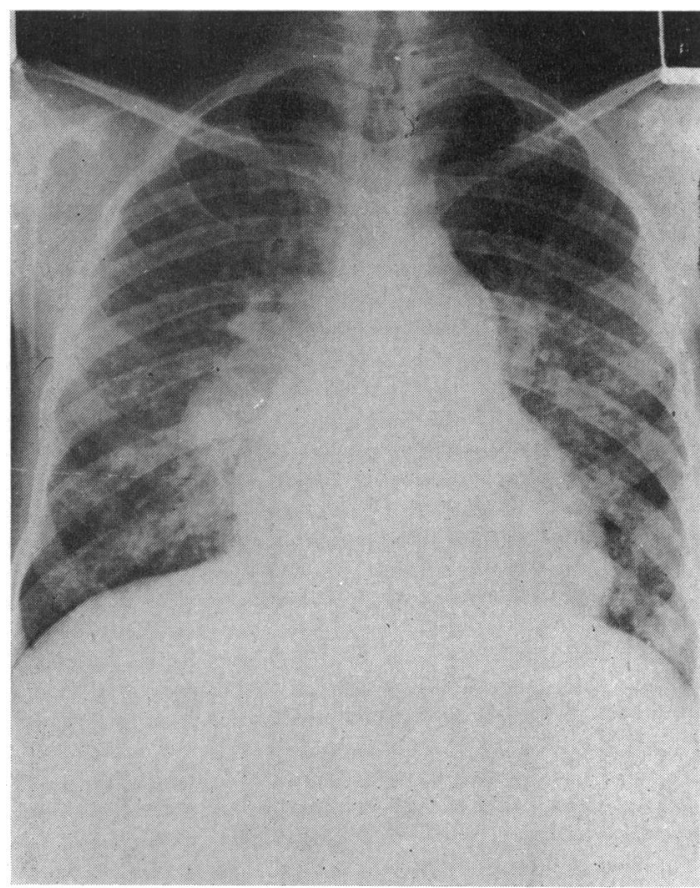

FIG. 2-Six-foot postero-anterior radiograph of the chest in Case 2. Right atrial and right ventricular enlargement, and very large pulmonary arteries. Miliary mottling in the lungs. second time were numerous ova of $S$. mansoni found. An adequate needle biopsy specimen of the liver showed no evidence of bilharzial cirrhosis. A lung biopsy (Fig. 3) taken at open operation was reported on as follows: "Lung tissue showing areas of collapse with scattered hæmosiderin-containing macrophages. The pulmonary vessels show both hypertrophy and intimal thickening. In some vessels the appearances suggest an organized thrombus. In one section there is an undoubted calcified schistosome egg". Right-sided cardiac catheterization was again confined to pressure readings. The right atrial pressure was $9 / 4$, right ventricular pressure $45 / 0 / 2$, and pulmonary artery pressure $45 / 20 \mathrm{~mm}$. Hg. The systemic arterial oxygen saturation was 95 per cent by Brinkman hæmoreflector.

Case 4. E.K., a Toro male, aged 20 years came from a district of Western Uganda which abuts on several lakes in which $S$. mansoni is known to occur. He complained of an unproductive cough and of breathlessness on exertion for two years. There had been no hæmoptysis until it occurred terminally. For two months he had had distension of the abdomen and swelling of his legs. On examination he was found to be in severe cardiac failure. There was considerable odema and some ascites. The jugular venous pressure was raised and there was a vigorous single systolic wave. The liver was enlarged to the level of the umbilicus and was pulsatile. The pulse was regular and of poor volume. The blood pressure was $100 / 90 \mathrm{~mm}$. $\mathrm{Hg}$. The heart was enlarged and there was a right ventricular heave; pulmonary closure was accentuated and at the tricuspid area a systolic murmur increasing with inspiration was heard. A systolic murmur was also heard at the mitral area where a thrill was also felt. It was concluded that the patient had pulmonary hypertension with congestive cardiac failure and functional tricuspid and mitral incompetence. Chest radiographs and fluoroscopy showed moderate cardiac enlargement with a large very active pulmonary conus and pulmonary main arteries. The peripheral vascular markings were considerably diminished. An electrocardiogram (Fig. 1) showed right axis deviation and inverted $\mathrm{T}$ waves over the præcordium, which may be the only cardiographic evidence of obliterative pulmonary arterial hypertension (Goodwin, Harrison, and Wilcken, 1963). The hæmoglobin was $9.7 \mathrm{~g} . / 100 \mathrm{ml}$. and there was no eosinophilia. No search for intestinal parasites was made. The only abnormality in the urine was albumin which gradually diminished in subsequent 


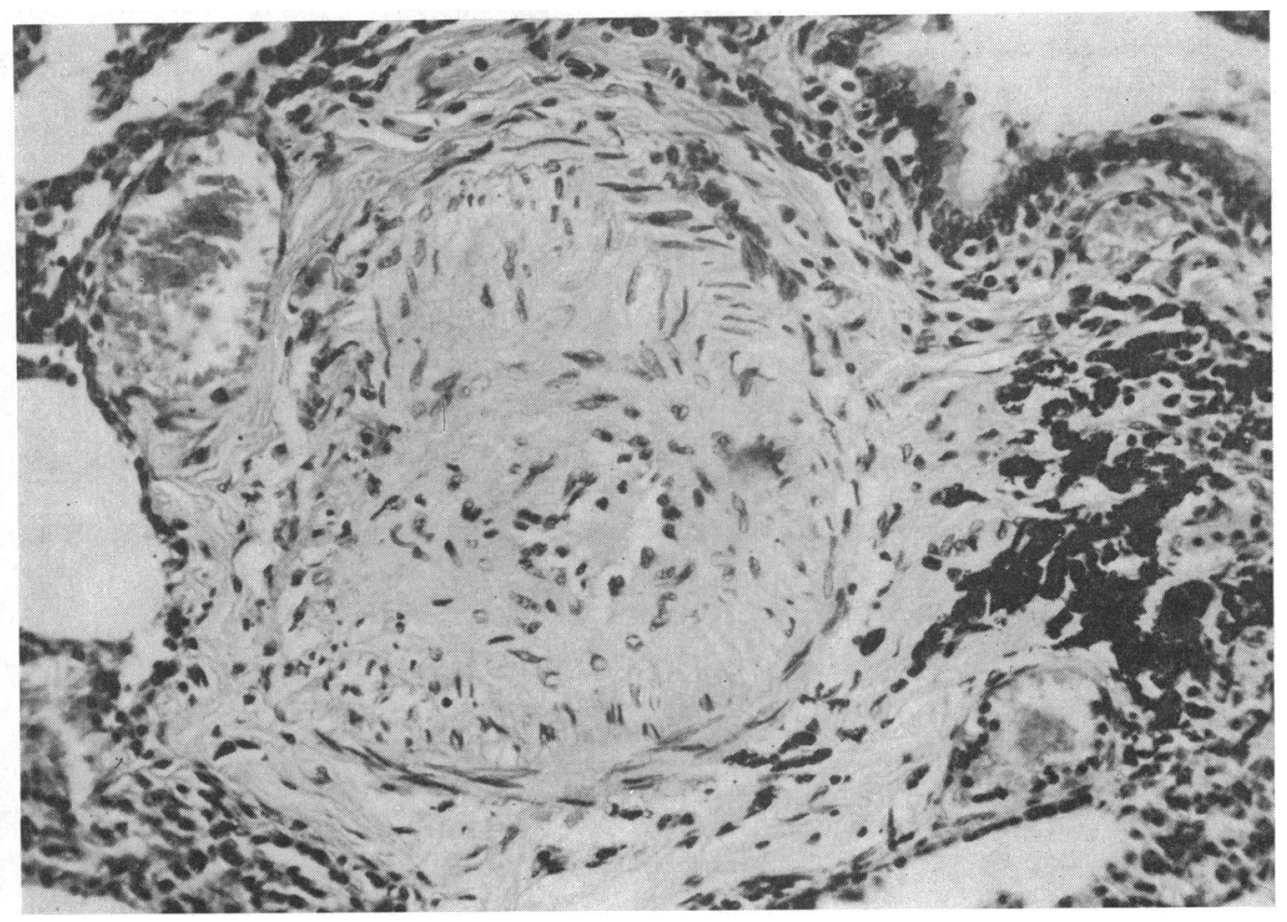

FIG. 3.--Lung biopsy of Case 3. Small pulmonary artery showing endothelial and fibroblastic proliferation of both the intima and the media. (Hæmatoxylin and eosin. $\times 300$.)

specimens. In spite of early improvement, the patient collapsed and died after two weeks in hospital. At necropsy confirmatory evidence of congestive heart failure was found. The right atrium and ventricle showed gross dilatation and hypertrophy, the left heart was normal. It was considered that the patient had primary pulmonary hypertension until the histology was subsequently reviewed. The sections (Fig. 4) showed extensive and severe changes. There was intimal and medial hypertrophy in the small pulmonary arterioles leading in many instances to almost complete obliteration. Angiomatoid formation was seen both within and without the pulmonary arterioles. In some places there were complex vascular structures composed partly of granulomatous tissue and partly of angiomatoid lesions. In the middle of one of these complex structures a schistosome ovum was seen. There can be little doubt that these were the changes of severe pulmonary hypertension due to schistosomiasis.

Case 5. P.B., a male Samia, aged 28 years, was born in Uganda, but belonged to a Kenya lacustrine tribe. He often visited his lakeside relatives, and stayed on occasion for as long as six months. In this area of Kenya, both $S$. mansoni and $S$. hamatobium are endemic. He complained that for eight months he had experienced substernal pain on exertion which radiated to the left side of the chest and to the left shoulder. Exertion also caused palpitations and breathlessness which was so severe that he had to sit down before resuming his activity. On examination there was no cyanosis or clubbing. The pulse volume was poor and the blood pressure $80 / 60 \mathrm{~mm}$. Hg. There was left parasternal pulsation, a palpable pulmonary second sound, and a loud ejection systolic murmur at the pulmonary area with marked accentuation of the second sound. A chest radiograph (Fig. 5) and fluoroscopy revealed aneurysmal enlargement of the pulmonary conus and of the right and left main pulmonary arteries which pulsated vigorously. There was some right-sided cardiac enlargement. The pulmonary arteries rapidly tapered off and the peripheral lung fields, particularly on the left, were remarkably clear. An electrocardiogram (Fig. 1), showed evidence of gross right ventricular hypertrophy, Grade 3 (Goodwin and Abdin, 1959). The hæmoglobin was $14.8 \mathrm{~g} . / 100 \mathrm{ml}$. There was an eosinophilia of 60 per cent of a total white cell count of 11,000 per c.mm. The urine was normal. Schistosome ova were not found in one specimen of stool. Unfortunately, the patient ran away before further investigation could be undertaken. He was seen in his home three years after this admission and had been 
working until one month before he was contacted. He complained of breathlessness and dizziness on exertion. On one occasion he had suddenly lost consciousness after exertion. He denied cough or hæmoptysis, was not cyanosed and had no clubbing of the fingers. The pulse was regular but of very poor volume, and the apex beat was in the fourth space $4 \frac{1}{2}$ inches from the midline. There was a marked left parasternal heave and a palpable second sound, with a loud ejection systolic murmur (Grade 4/6), widely heard over the præcordium but maximal at the pulmonary area; an ejection click was heard. The basal second sound was narrowly split and the pulmonary element very loud. There was no diastolic murmur. Unfortunately, in spite of his promises, he did not come into hospital again.

Fig. 5.-Six-foot postero-anterior radiograph of the chest in Case 5 . Very large pulmonary arteries with truncation of the branches and oligæmic lung fields, particularly on the left. Enlargement of the right ventricle.

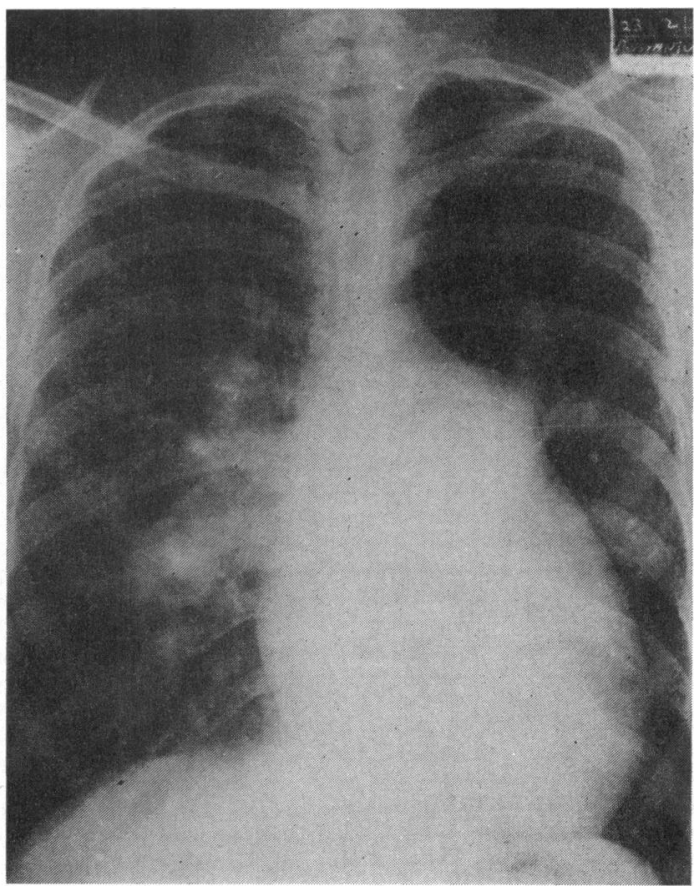




\section{DISCUSSION}

Pulmonary heart disease at the Kenya coast has been discussed previously (Turner, 1962). However, in spite of the high endemicity of $S$. hamatobium in this area, at that time no example of pulmonary arterial hypertension from this cause had been seen. The first example from this part of East Africa is described in this paper (Case 1). In Uganda only one case of this disease has been described before (Williams, 1958), and this patient was seen as long ago as 1953, and the diagnosis was only made at necropsy. Four new cases from Uganda are presented here though one is of a Kenya tribe. Three of the cases were diagnosed during life. Three were due to S. mansoni; the causal schistosome in the fourth is uncertain. These cases were seen over a period of four years, so that the incidence of this complication seems to be much lower than it is in Egypt and South America. It is said that $S$. hamatobium reaches the lungs more readily, but that $S$. mansoni produces the more severe effects (Shaw and Ghareeb, 1938). The ova of $S$. hamatobium can readily reach the lungs from the vesical plexus via the systemic veins, but the route of the ova of $S$. mansoni is more difficult to determine. Most of the cases seen in Egypt due to $S$. mansoni also have severe cirrhosis of the liver and vascular communications between the portal and systemic veins within the liver have been postulated. However, in the cases described here there was no evidence of severe cirrhosis of the liver. Gelfand (1950) noted that when ova of $S$. mansoni were found in the lungs the worm was also present in the venous plexuses of the bladder, so that the same route followed by the ova of $S$. hamatobium could be used. This may well have been so in these cases from Uganda and would more easily explain how the lungs were involved.

Diagnosis should not be difficult. Pulmonary arterial hypertension can readily be diagnosed on clinical grounds. If there is no apparent cause, then in areas where schistosomiasis occurs the possibility, indeed, the probability, of this as a cause must be considered. Finding the ova of $S$. hamatobium or of $S$. mansoni in the urine or stool gives a helpful lead, but is not diagnostic. It may be necessary to search persistently for such evidence. More suggestive is the finding of ova in the sputum. Nor el Din and El Baz (1954) found ova in the sputum of 22 of 62 cases of bilharzial disease. They stated that in most of those with ova in the sputum there was radiographic evidence suggestive of lung bilharziasis. However, one needs to know how often ova are found in the sputum without there being evidence of lung involvement or of pulmonary hypertension. The best diagnostic evidence is provided by histological material obtained either at necropsy or from lung biopsy. The presence of angiomatoid formation has been regarded as diagnostic of schistosomal pulmonary hypertension (Shaw and Ghareeb, 1938), but this is not so. Similar changes occur in the more severe grade of pulmonary hypertension from other causes (Heath and Edwards, 1958). Brewer (1955) compared the histological changes in a case of pulmonary hypertension in association with a patent ductus arteriosus with those of the example of bilharzial hypertension from Uganda described by Williams (1958) and found them to be similar. However, histological evidence of pulmonary hypertensive lesions in close association with schistosome ova and granulomata may reasonably be accepted as proof. It is not surprising that embolization of small pulmonary vessels with schistosome ova should produce obstructive pulmonary hypertension, since it is now thought that multiple small emboli from peripheral venous thrombosis may also cause it (Goodwin et al., 1963). Pulmonary arterial hypertension can also be produced experimentally using barium sulphate particles, glass balls, or lycopodium spores as the source of emboli.

The loss of consciousness on exertion which was also observed by Cavalcanti et al. (1962) and occurs in pulmonary hypertension from other causes (Goodwin et al., 1963) is presumably due to a relatively fixed cardiac output and a failure to increase adequately with exercise. Unfortunately, cardiac outputs were not estimated in this small series. Some evidence to support this concept was produced by the study of Farid et al. (1959).

The physical signs are those of pulmonary arterial hypertension. However, in two of the cases, delayed pulmonary valve closure was observed, the basal second sound being widely split instead of narrowly split or single as is usual in pulmonary hypertension. The reason for this is obscure. There was no evidence of right bundle-branch block (Fig. 1, Cases 2 and 3). A feature of this 
disease is the almost aneurysmal dilatation of the pulmonary artery. Indeed, it has been suggested (Zaky, El-Heneidy, and Foda, 1962) that this is out of proportion to the degree of pulmonary hypertension observed. It was, therefore, postulated in the cases described here that there might be a fall of pressure across the pulmonary valve from the right ventricular outflow tract into the widely dilated pulmonary artery and therefore delayed pulmonary valve closure. However, no evidence of any pressure gradient was found at catheterization. In describing 19 cases with thrombo-embolic obliterative hypertension, Goodwin et al. (1963), described an Egyptian woman who differed from the general clinical picture presented by their patients, by having a soft and delayed pulmonary valve closure sound. Schistosomiasis as a cause of this woman's obliterative pulmonary hypertension was. considered, but no suggestive evidence was found (J. F. Goodwin, personal communication 1963). No evidence has been found among the published reports that delayed closure of the pulmonary second sound has been considered before, though some authors (Cavalcanti et al., 1962; Rodríguez et al., 1963) mention that the pulmonary second sound was split without saying whether it was abnormally wide or not.

The electrocardiogram shows evidence of considerable right ventricular hypertrophy. This is mostly of the pattern described by Goodwin and Abdin (1959) and can be graded according toseverity as suggested by them. However, in obliterative pulmonary hypertension dominant $\mathrm{R}$ waves may be absent over the right ventricle and the presence of inverted $T$ waves over the right. præcordium may be the only evidence of even severe degrees of pulmonary hypertension (Goodwin et al., 1963). It is interesting to note that this pattern was seen in one of the cases reported here (Fig. 1, Case 4) in whom the histology (Fig. 4) suggested an extremely severe degree of pulmonary hypertension (Grade 6 of Heath and Edwards, 1958). The P waves are usually normal, though occasional evidence of right atrial hypertrophy is seen. Indeed, Girgis (1952) states that this occurred in 6 of his 7 cases. In this series $P$ waves denoting true right atrial enlargement were not seen. Cavalcanti et al. (1962) say that the electrocardiogram is similar to that in primary pulmonary hypertension, except that there is not the increasing negativity of the T waves from V2 to V4 seen in that condition. In the present series increasing negativity of the $T$ waves from V2 to V4 was seen on three occasions (Fig. 1, Case 3, 4, and 5), so that this does not seem to be a valid difference. Striking $\mathrm{T}$ wave changes are usual, as they also are in thrombo-embolic pulmonary hypertension (Goodwin et al., 1963): this is in contrast to the usual finding in cor pulmonale from obstructive airways disease (Caird and Stanfield, 1962).

Radiology reveals evidence of pulmonary arterial hypertension, the heart is only slightly enlarged unless heart failure is present. There may be evidence of right atrial and ventricular enlargement. The main pulmonary arteries are much enlarged but are truncated and the peripheral lung fields are clear because of the relative absence of vascular markings (Fig. 5). It has been stated that the large pulmonary arteries are not unduly pulsatile and this has been suggested as a differential diagnostic point between this condition and atrial septal defect. That this is not so was pointed out by Cavalcanti et al. (1962), and in two of the cases described here the large pulmonary arteries were vigorously pulsatile. In occasional cases the miliary shadows of the schistosomal granulomata are seen (Fig. 2). These are probably partly due to an intense allergic reaction that occurs round the granulomata at times when further infestation is taking place.

Right heart catheterization reveals the severity of the pulmonary hypertension and provides evidence of the increased pulmonary vascular resistance and diminished pulmonary flow which is characteristic of the condition. Right atrial traces are usually normal in the absence of heart failure (Cavalcanti et al., 1962). However, the mean pressure may be raised and the "a" wave prominent even in the absence of heart failure and with a normal end-diastolic pressure in the right ventricle (Kaplan, 1959). The "a" wave was prominent in both the patients in this series who were catheterized, though neither was in heart failure. In Case 2, the more severe of the two catheterized, the end-diastolic right ventricular pressure was raised. Evidence of a left-to-right shunt may be noted (Zaky et al., 1962), but was not found by Cavalcanti et al. (1962) nor by Rodríguez et al. (1963). Low arterial oxygen saturation which does not increase on inhalation of 100 per cent oxygen has 
often been found (Cavalcanti et al., 1962), and suggests a right-to-left shunt through pre-capillary vascular anastomoses in the lungs, though a patent foramen ovale might also allow such a shunt.

The histological picture has been well described by a number of authors, but never better than in the early paper by Shaw and Ghareeb (1938). The ova obstruct the small pulmonary vessels through the walls of which they then pass. The tissue reaction which they induce leads to an obliterative pulmonary arteriolitis in the vessel and to extravascular granulomata, in the middle of which ova or their remains may often be seen. Re-canalization occurs in the obliterated vessel and around it the thin-walled angiomatoid and other "dilatation" lesions described by Shaw and Ghareeb (1938). These are also seen in pulmonary hypertension from other causes (Brewer, 1955; Heath and Edwards, 1958). Such secondary vascular abnormalities presumably allow the shunting of blood from pulmonary to systemic or from systemic to pulmonary circulation.

Minor degrees of clubbing of the fingers occur occasionally and are mentioned by a number of writers (Erfan et al., 1949; Kenawy, 1950; Marchand et al., 1957; Ogunlesi, 1962). In two of the series reported here (Cases 2 and 3) clubbing was present, and in one it was marked: it is not necessarily related to cyanosis, for in these two cases the arterial oxygen saturation was normal even after exercise in the more severe (Case 2). Cudkowicz and Wraith (1957a) investigated finger clubbing in a variety of lung diseases, and included studies of arterial oxygen saturation, finding no common clinical factor between them. In 1953, Cudkowicz and Armstrong found histological evidence of pre-capillary bronchial anastomoses in patients with lung diseases, and later Cudkowicz and Wraith (1957b) demonstrated that the oxygen saturation was abnormally high in the pulmonary arteries perfusing abnormal lobes of the lungs in patients with lung disease and clubbing. They considered this to be evidence of pre-capillary bronchial anastomoses in the abnormal lobes. Vascular abnormalities such as dilated, thin-walled channels and angiomatoid lesions are a feature of severe pulmonary hypertension (Brewer, 1955; Heath and Edwards, 1958). Such vascular changes are a marked feature of schistosomal pulmonary hypertension (Shaw and Ghareeb, 1938). Presumably, in such thin-walled, low pressure vascular channels shunts may occur from the pulmonary artery to the pulmonary vein and thence to the systemic circulation. The occurrence has often been seen of arterial oxygen desaturation, which does not respond to inhalation of 100 per cent oxygen in schistosomal pulmonary hypertension (Cavalcanti et al., 1962). This suggests that it is due to a right-toleft shunt through abnormal vascular communications in the lung and not to imbalance between ventilation and perfusion. It could be explained by a shunt through a patent foramen ovale, but seems to occur too often for this to be a reasonable explanation. It is also true that the mean right atrial pressure is usually normal so there is no reason why a right-to-left shunt should occur even were the foramen ovale patent, though it is conceivable that this might occur after exertion. That such right-to-left shunts may explain clubbing has been postulated by Hall (1959) and by Hall and Laidlaw (1963), who have also produced interesting experimental evidence to support their thesis. The suggestion of Hall (1959) is that reduced ferritin escapes oxidation by bypassing the lungs via the pre-capillary anastomoses and reaches the systemic circulation in its vaso-active form, producing clubbing by antagonizing the vaso-constrictor action of the normally circulating adrenaline on the arterio-venous anastomoses known to exist in the finger tips, toes, and nose. Such a mechanism could clearly operate in schistosomal pulmonary hypertension. However, a weakness of this explanation is that since the lungs are diffusely involved clubbing should be more severe with the greater degrees of right-to-left shunting and therefore with arterial desaturation. This does not seem to be so in practice. It is of some interest that Lopes de Faria et al. (1957) described two cases with $S$. mansoni and numerous arteriovenous fistulæ in the lungs which gave rise to clinically obvious central cyanosis and clubbing, and yet at necropsy there was little evidence of right-sided heart involvement.

Evidence for left-to-right shunting in schistosomiasis has been provided by Zaky et al. (1962). They found that the oxygen saturation increased steadily as the catheter was moved from the prewedge position to the main pulmonary artery in three cases. They also demonstrated an abnormal flow from the aorta to the pulmonary artery via the bronchial arteries using aortography and a dye 
dilution technique. But Cavalcanti et al. (1962) and Rodríguez et.al. (1963) found no evidence of a left-to-right shunt. One must conclude that abnormal communications exist between the pulmonary artery, pulmonary vein, and bronchial arteries and that shunts in either or both directions may occur.

Zaky et al. (1962) say that the enlargement of the pulmonary arteries is out of all proportion to the measured pressure. They postulate that this enlargement is partly due to high flow, the additional blood coming from the left-to-right shunts in the lungs, and from similar shunts in the spleen. This seems difficult to believe, for though the evidence for right-to-left shunts via the lungs is good the sum total volume shunted in any particular direction must be minimal. The need for further careful hæmodynamic investigation is obvious. It is likely that studies of lung perfusion and ventilation will also be rewarding.

The ultimate prognosis must be poor, though certain patients seem to tolerate the condition for some years before the heart fails. Treatment may prevent further embolization but it is unlikely to have any effect on the already obliterated pulmonary arteries.

\section{CONCLUSIONS}

Pulmonary arterial hypertension due to $S$. mansoni and to $S$. hamatobium occurs more frequently in East Africa than has previously been thought, though it is not as common as in Egypt. It is not necessary for cirrhosis of the liver to be present to allow the ova of $S$. mansoni to reach the pulmonary arterioles. Possibly the worm is present in the vesical venous plexuses as well as in those of the gut, thus allowing the ova to take the systemic route used by those of S. hamatobium.

In areas where schistosomiasis is endemic the occurrence of pulmonary arterial hypertension without obvious cause should strongly suggest the probability of its being due to embolization of the pulmonary arterioles with schistosome ova. The search for confirmatory evidence may be difficult; looking for ova in the sputum may be rewarding. It is reasonable to accept histological evidence of pulmonary arterial hypertension together with schistosome ova and granulomata as proof that the ova are causative, but angiomatoid formation alone is not pathognomonic of schistosomal pulmonary arterial hypertension.

Loss of consciousness or giddiness on exertion is common and is presumably due to a failure of the already low cardiac output to increase with exercise. Anginal pain may also occur for the same reason.

The physical signs are similar to those seen in obliterative pulmonary arterial hypertension from other causes. However, pulmonary valve closure may be delayed and unusual systolic murmurs may be heard for reasons which are at present not known. Clubbing of the fingers may occur even without arterial oxygen desaturation; the reason for this is obscure.

The electrocardiogram does not differ from that in thrombo-embolic and primary pulmonary hypertension, and increasing negativity of the $T$ waves from V2 to V4 is commonly seen. Marked $T$ wave changes are usual and are similar to those seen in thrombo-embolic pulmonary arterial hypertension.

The large main pulmonary arteries may be seen to be very pulsatile, sometimes tending to resemble the appearances in atrial septal defect. Miliary shadows may be seen in the chest radiograph. and are helpful in diagnosis. It is suggested that they are due to an allergic reaction around the small schistosomal granulomata, occurring particularly at times of further infestation with schistosomes.

There is evidence that in schistosomal pulmonary arterial hypertension, abnormal communications exist between the pulmonary artery, pulmonary vein, and the bronchial arteries, and that blood may be shunted through them in either or both directions. However, many features of this condition are still not understood and further hæmodynamic and lung function studies are needed.

Since severe structural damage has occurred by the time the diagnosis is made, treatment is unlikely to be effective except in as much as it may prevent further embolization. 


\section{SUMMARY}

Five new cases of schistosomal pulmonary hypertension from East Africa are described, one from the Kenya coast and four from Uganda. Three of those from Uganda were due to $S$. mansoni and that from Kenya to $S$. hamatobium. In one case the causal schistosome is uncertain. The clinical and hæmodynamic features are discussed and particular attention is paid to clubbing, to the delayed closure of the pulmonary second sound, and to the apparent occurrence of shunts in both directions through pre-capillary vascular communications between the pulmonary artery, pulmonary vein, and bronchial arteries. The difficulties of diagnosis are stressed. It is shown that cirrhosis of the liver is not necessary for pulmonary arterial hypertension to develop in $S$. mansoni infestation.

I should like to thank my colleagues Drs. A. G. Shaper and J. Banwell for referring cases to me, Professor C. V. Harrison of the Postgraduate Medical School, London, Professor M. S. R. Hutt and Dr. D. H. Connor of the Department of Pathology, Makerere University College Medical School, for their histological reports, Dr. D. L. Price of the Walter Reed Army Institute of Research, Washington, D.C., for his help in finding ova in the sputum, Mr. H. Rothe, lately of Kenya, and Mr. P. Ashman James of Uganda for performing lung biopsies, Mr. R. C. Wellingham for the radiological and electrocardiographic illustrations, and Mr. R. Tunnicliffe, F.I.M.L.T. for the histological illustrations.

\section{REFERENCES}

Bedford, D. E., Aidaros, S. M., and Girgis, B. (1946). Bilharzial heart disease in Egypt: Cor pulmonale due to bilharzial pulmonary endarteritis. Brit. Heart J., 8, 87.

Brewer, D. B. (1955). Fibrous occlusion and anastomosis of the pulmonary vessels in a case of pulmonary hypertension associated with patent ductus arteriosus. J. Path. Bact., 70, 299.

Caird, F. I., and Stanfield, C. A. (1962). The electrocardiogram in asphyxial and in embolic acute cor pulmonale. Brit. Heart J., 24, 313.

Cavalcanti, I. de L., Tompson, G., De Souza, N., and Barbosa, F. S. (1962). Pulmonary hypertension in schistosomiasis. Brit. Heart J., 24, 363.

Clark, E., and Graef, I. (1935). Chronic pulmonary arteritis in schistosomiasis mansoni associated with right ventricular hypertrophy. Amer. J. Path., 11, 693.

Cudkowicz, L., and Armstrong, J. B. (1953). Finger clubbing and changes in the bronchial circulation. Brit. J. Tuberc., 47, 227.

—, and Wraith, D. G. (1957a). An evaluation of the clinical significance of clubbing in common lung disorders. Brit. J. Tuberc., 51, 14.

-, and - (1957b). A method of study of the pulmonary circulation in finger clubbing. Thorax, $12,313$.

Day, H. B. (1937). Pulmonary bilharziasis. Trans. roy. Soc. trop. Med. Hyg., 30, 575.

Edington, G. M. (1957). Schistosomiasis in Ghana with special reference to its pathology. W. Afr. med. J., 6, 45.

Erfan, M., Erfan, H., Mousa, A. M. and Deeb, A. A. (1949). Chronic pulmonary schistosomiasis: A clinical and radiological study. Trans. roy. Soc. trop. Med. Hyg., 42, 477.

Farid, Z., Greer, J. W., Ishak, K. G., El Nagah, A. M., LeGolvan, P. C., and Mousa, A. H. (1959). Chronic pulmonary schistosomiasis. Amer. Rev. Tuberc., 79, 119.

Gelfand, M. (1950). Schistosomiasis in South Central Africa. Juta, Cape Town and Johannesburg.

(1957). Cor-pulmonale and cardio-pulmonary schistosomiasis. Trans. roy. Soc. trop. Med. Hyg., $51,533$.

Girgis, B. (1952). Pulmonary heart disease due to bilharzia: The bilharzial cor pulmonale. Amer. Heart J., 43, 606.

Goodwin, J. F., and Abdin, Z. H. (1959). The cardiogram of congenital and acquired right ventricular hypertrophy. Brit. Heart J., 21, 523.

- Harrison, C. V., and Wilcken, D. E. L. (1963). Obliterative pulmonary hypertension and thrombo-embolism. Brit. med. J., 1, 701 and 777.

Hall, G. H. (1959). The cause of digital clubbing; testing a new hypothesis. Lancet, 1, 750.

, and Laidlaw, C. D'Arcy (1963). Further experimental evidence implicating reduced ferritin as a cause of digital clubbing. Clin. Sci., 24, 121.

Heath, D., and Edwards, J. E. (1958). The pathology of hypertensive pulmonary vascular disease-a description of six grades of structural changes in the pulmonary arteries with special reference to congenital cardiac septal defects. Circulation, 18, 533 .

Kaplan, S. (1959). Pressure curve analysis. In Intra Vascular Catheterization, ed. H. A. Zimmerman, pp. 80-139. Charles C. Thomas, Springfield, Illinois.

Kenawy, M. R. (1950). The syndrome of cardiopulmonary schistosomiasis (cor pulmonale). Amer. Heart J., $39,678$.

Lauckner, J. R., Rankin, A. M., and Adi, F. C. (1961). Analysis of medical admissions to University College Hospital, Ibadan-1958. West Afr. med. J., 10, 3.

Lopes de Faria, J., Czapski, J., Ribeiro Leite, M. O., de Oliveira Penna, D., Fujioka, T., and de Ulhôa Cintra, A. B. (1957). Cyanosis in Manson's schistosomiasis: Role of pulmonary schistosomatic arteriovenous fistulas. Amer. Heart J., 54, 196. 
Marchand, E. J., Marcial-Rojas, R. A., Rodríguez, R., Polanco, G., and Díaz-Rivera, R. S. (1957). The pulmonary obstruction syndrome in Schistosoma mansoni pulmonary endarteritis. Arch. intern. Med., 100, 965.

Nor el Din, G., and El Baz, I. (1954). Sputum examination in the diagnosis of bilharziasis of the lungs. Amer. J. trop. Med. Hyg., 3, 326.

Ogunlesi, T. O. (1962). Schistosomiasis and cor-pulmonale in West Africa. Trans. roy. Soc. trop. Med. Hyg., 56, 302.

Rodríguez, H. F., Fernández-Durán, A., García-Moliner, L., and Rivera, E. (1963). Cardiopulmonary schistosomiasis. Amer. Heart J., 65, 253.

Shaw, A. F. B., and Ghareeb, A. A. (1938). The pathogenesis of pulmonary schistosomiasis in Egypt with special reference to Ayerza's disease. J. Path. Bact., 46, 401

Turner, P. P. (1962). Pulmonary heart disease in Africans in Mombasa. E. Afr. med. J., $39,40$.

Williams, A. W. (1958). Cor pulmonale in schistosomiasis. E. Afr. med. J., 35, 1.

Zaky, H. A., El-Heneidy, A. R., and Foda, M. T. (1962). Hæmodynamic shunts in schistosomal cor pulmonale. Brit. med. J., 1, 367. 